\title{
A Quem Serve a Participação? Experiência democrática do Fórum Interconselhos no Plano Plurianual 2016-2019'
}

Daniel Pitangueira de Avelino²

Eduardo Gomor dos Santos ${ }^{3}$

Felipe Portela Bezerra ${ }^{4}$

\section{INTRODUÇ̃̃̃O}

A Lei de Responsabilidade Fiscal (LRF), de 2000, tornou obrigatória a participação popular durante os processos de elaboração e discussão dos planos e das leis orçamentárias (art. $48, \mathbb{1}$ 1, inciso I). ${ }^{5}$ Inspirado em iniciativas municipais e estaduais, como o orçamento participativo, o governo federal somente concretiza esse princípio nas audiências e consultas sobre a elaboração do Plano Plurianual (PPA), em 2003 e 2007. Por fim, em 2011, é criado o Fórum Interconselhos, ativo até 2017.

Tem-se como objetivo neste texto descrever e analisar as estratégias de participação social na elaboração e no monitoramento do PPA 2016-2019. Especificamente, tenta-se identificar fatores que levaram ao posterior abandono dessas práticas.

Após esta introdução, na seção 2 são descritas as estratégias de participação anteriores, na seção 3, a elaboração do PPA 2016-2019, na seção 4, seu monitoramento, e, sucintamente, na seção 5, a elaboração do PPA seguinte. De forma analítica, são identificados, na seção 6, os fatores que contribuíram para manutenção e desuso dessas práticas, e a última seção traz algumas reflexôes sobre participação e planejamento público.

Em síntese, o estudo conclui que a participação social no planejamento público federal passou por um momento de ascensão e hoje vive um declínio. A falta de institucionalização é identificada como principal fator de desuso, sendo mitigada enquanto havia uma funçáo de planejamento fortalecida e uma equipe técnica comprometida, mas se mostrando decisiva quando o cenário político passou a ser desfavorável à participação e ao planejamento.

\section{PRECEDENTES}

Os processos participativos realizados pelo governo federal em 2003 e 2007 inauguraram uma tradição democrática no planejamento federal, em cumprimento à LRF. A elaboração do PPA 2004-2007 envolveu audiências públicas e regionalizadas e o PPA 2008-2011 inaugurou a prática de consultas aos conselhos nacionais. Essas práticas foram, contudo, criticadas pelos participantes, pelo seu caráter episódico e descontínuo e pela falta de informaçôes sobre o acatamento às demandas apresentadas.

1. DOI: http://dx.doi.org/10.38116/bapi28art4

2. Especialista em políticas públicas e gestão governamental na Diretoria de Estudos e Políticas do Estado, das Instituições e da Democracia (Diest) do Ipea.

3. Analista de planejamento e orçamento; e pesquisador do Núcleo de Estudos e Pesquisas em Política Social da Universidade de Brasília (NEPPOS/UnB).

4. Professor de administração pública no Instituto Brasiliense de Direito Público (IDP); e técnico administrativo em educação na UnB.

5. Disponível em: <http://www.planalto.gov.br/ccivil_03/leis/lcp/lcp101.htm>. 
Logo, em 2011, havia o desafio de desenhar uma estratégia mensurável de contribuição à elaboração do PPA 2012-2015, sem competir com o nível de participação existente.

Na solução adotada, batizada como Fórum Interconselhos, conselheiros representantes da sociedade civil, indicados por seus colegiados, foram convidados a uma assembleia, em maio de 2011. Nessa oportunidade, puderam discutir de forma mais ampla as demandas trazidas dos seus conselhos e de suas entidades e a partir disso formular propostas específicas (sem limite de quantidade) para o PPA 2012-2015. Na segunda edição, em outubro daquele ano, o governo respondeu às recomendaçóes recebidas e, nas etapas posteriores, anualmente de 2012 a 2014, houve o monitoramento das agendas transversais ${ }^{6}$ do plano. Justamente por ser um fórum, esse ambiente de participação trazia em si uma menor rigidez quanto à composiçáo dos participantes e à periodicidade de reunióes se comparado a instituiçôes participativas mais tradicionais, como os conselhos e as conferências. A prioridade era a garantia de ampla representatividade, recorrendo a pessoas que apresentavam diferentes trajetórias em experiências distintas de participação social.

Essa metodologia conquistou reconhecimento com o tempo. No cenário nacional, o método interconselhos foi adotado em outros contextos e, com a instituição do sistema e da Política Nacional de Participação Social (Decreto no 8.243, de 2014, revogado em 2019), foi citado como mecanismo de participação social do governo federal. Internacionalmente, o fórum integrou compromissos assumidos nos planos de ação brasileiros da Parceria para Governo Aberto (Open Government Partnership OGP) e, em 2014, conquistou o Prêmio de Serviço Público das Naçóes Unidas (United Nations Public Service Awards - UNPSA) como inciativa inovadora de promoção da participação. Nesse contexto, percebe-se que havia um potencial caminho de desenvolvimento e continuidade dessa estratégia participativa no PPA seguinte.

\section{ELABORAÇÃO DO PPA 2016-2019}

Na formulação do PPA 2016-2019, a estratégia foi rebatizada como Fórum Dialoga Brasil. A primeira reunião, em abril de 2015, marcou o início da contribuição da sociedade, principalmente em âmbito estratégico, com 378 participantes oficialmente registrados, sendo 246 vinculados a conselhos ou a entidades e 132 pertencentes ao quadro de governos municipais, estaduais ou federal. Inicialmente, o governo dividiu as demandas em oito grupos temáticos, focados em áreas, para alcançar o objetivo de que esse encontro tivesse como resultado futuro a elaboração de uma forma de monitoramento da implementação do plano e a revisão das agendas transversais. Também foram realizadas audiências regionais e setoriais.

Ao todo, foram apresentadas 1.050 propostas para a elaboração do projeto de lei do PPA. Observa-se que a interação com a sociedade passava a ganhar dimensões maiores, considerando a regionalização que o fórum alcançou, de maneira a permitir a inclusão de demandas diversas de todo o país. Após tais ediçóes, em julho de 2015 houve mais uma reunião, baseada na apresentação de um relatório de devolutiva (Brasil, 2015), apresentado pelo governo, para que as pessoas pudessem verificar a forma de inserção de cada demanda como elemento do PPA, assim como demonstrar aquelas que não tinham sido incluídas.

6. As agendas transversais foram uma das principais inovações do PPA 2012-2015, apresentando formas alternativas de organização das demandas intersetoriais, para as temáticas de: criança e adolescente; juventude; pessoa idosa; políticas para as mulheres; pessoa com deficiência; população LGBT (lésbicas, gays, bissexuais, travestis, transexuais e transgêneros); população em situação de rua; igualdade racial, comunidades quilombolas e povos e comunidades tradicionais; e povos indígenas. 
QUADRO 1

Audiências regionais e setoriais do Fórum Dialoga Brasil e números de participantes (2015)

\begin{tabular}{|l|l|c|c|}
\hline \multicolumn{1}{|c|}{ Data } & \multicolumn{1}{|c|}{ Região } & Participantes & Entidades presentes \\
\hline $22 / 5 / 2015$ & Nordeste - Salvador & 663 & 120 \\
\hline $28 / 5 / 2015$ & Sul - Porto Alegre & 511 & 159 \\
\hline $29 / 5 / 2015$ & Sudeste - Belo Horizonte & 558 & 51 \\
\hline $2 / 6 / 2015$ & Centro-Oeste - Goiânia & 637 & 202 \\
\hline $10 / 6 / 2015$ & Norte - Belém & 755 & 160 \\
\hline $11 / 6 / 2015$ & Nordeste - Fortaleza & 621 & 933 \\
\hline Total nos fóruns regionais & & 3.745 & Entes presentes \\
\hline \multicolumn{1}{|c|}{ Data } & & Participantes & 60 \\
\hline $16 / 6 / 2015$ & Mulheres & 122 & 33 \\
\hline $18 / 6 / 2015$ & Juventude & 86 & 39 \\
\hline $29 / 6 / 2015$ & Sindical & 92 & 24 \\
\hline $29 / 6 / 2015$ & Empresarial & 35 & 156 \\
\hline Total nos fóruns setoriais & & 335 & 1.089 \\
\hline Total geral nos fóruns & & 4.080 & \\
\hline
\end{tabular}

Fonte: Brasil (2015).

Elaboração dos autores.

As demandas da sociedade, em geral, apresentavam caráter amplo e genérico. Como exemplo, a primeira contribuição registrada no grupo para o Sistema Único de Assistência Social (SUAS) foi assegurar o cofinanciamento para garantir os serviços da assistência. Em resposta, o governo propóe um objetivo e uma iniciativa, no PPA, que tratam, respectivamente, de "fortalecer e qualificar a gestão do SUAS e os mecanismos democráticos de participação e controle social" e de "definir parâmetros de equidade no cofinanciamento federativo da oferta dos serviços do SUAS, em consonância com o custo dos serviços" (Brasil, 2015, p. 113). É possível verificar que tal demanda se refletiu em previsões concretas no âmbito do PPA, logo, passou a integrar as políticas e açóes governamentais e precisava ser acompanhada, também, pela sociedade civil, a fim de garantir a materialização de sua proposição.

Essa estrutura de prestação de contas, aberta e transparente, marcou o início de um potencial meio de controle social do planejamento governamental. A inovação nessa dinâmica de participação ganhou destaque devido a uma consolidação que se construía para as contribuiçóes da sociedade ao PPA, deixando de atribuir a formulação do planejamento, em âmbito federal, apenas ao corpo técnico ou a iniciativas isoladas e pontuais de participação. Em comparação aos PPAs anteriores, essas ediçóes do fórum demonstraram amadurecimento e ampliação de um sistema de participação transversal a nível federal.

\section{MONITORAMENTO DO PPA 2016-2019}

O fórum de março de 2016 discutiu práticas de monitoramento do PPA. Foram definidas, então, doze agendas temáticas para serem acompanhadas pela sociedade civil, divididas em áreas como igualdade racial, economia solidária, criança e adolescente. Nesse contexto, o governo apresentou um documento (Brasil, 2016) com orientaçóes para que os participantes pudessem manter continuamente as atividades de monitoramento junto às suas entidades e aos seus colegiados. Essa forma de incentivo ao acompanhamento demonstrava que o fórum buscava consolidar a interação entre Estado e 
sociedade para além de suas reunióes, o que fortaleceria a capacidade dos atores envolvidos no tema para desenvolver um monitoramento sistemático do PPA.

Em maio de 2016, com o novo PPA em vigor, houve o afastamento da presidenta eleita. Após alteraçóes na estrutura do governo federal, a estratégia de participação foi retomada. Inicialmente, foi fortalecida a transparência por meio de aplicativos digitais (como o PPA Cidadão) e de relatórios temáticos, incluindo as agendas temáticas do PPA anterior e os novos temas, vinculados à agenda dos Objetivos do Desenvolvimento Sustentável (ODS). Depois de sua aprovação em 2015, o conteúdo dos ODS, que é parte da Agenda 2030 da Organização das Naçóes Unidas (ONU), foi comparado com o do PPA 2016-2019, em um processo de alinhamento estratégico realizado em parceria entre o então Ministério do Planejamento, Desenvolvimento e Gestão e a Secretaria de Governo da Presidência da República (Segov), envolvendo a participação de 29 ministérios/secretarias nacionais e cerca de 250 servidores federais (Brasil, 2018, p. 34).

O processo resultou em uma base de dados que identificou as relaçóes entre as metas dos ODS e as metas e iniciativas do PPA 2016-2019, permitindo uma visão sistêmica das açóes do governo federal para o alcance de cada um dos ODS. Importante destacar o alto nível de aderência entre os dois elementos, sendo que 161 das 169 metas dos ODS, cerca de 95\%, possuíam algum atributo do PPA relacionado à sua implementação. Além do PPA Cidadão, as agendas dos ODS foram inseridas também no âmbito do Sistema Integrado de Planejamento e Orçamento (SIOP), possibilitando o acesso às informações para toda a administração pública (Brasil, 2018).

Outra ação envolvia os conselhos nacionais como agentes de monitoramento do PPA. A partir do diagnóstico de que a elaboração das metas do PPA contemplava a contento as demandas da sociedade civil, ${ }^{7}$ o foco se voltou então para aperfeiçoar sua atuação no monitoramento da execução das políticas públicas. Para isso, o modelo vigente se mostrava insuficiente, na medida em que o controle social ocorria apenas ao final de cada ano, com a apresentação dos relatórios de monitoramento do PPA elaborados por cada órgão. Essa sistemática se aproximava mais de uma prestação de contas do que de um modelo efetivo de monitoramento, que possibilitasse a correçáo tempestiva dos rumos da execução das políticas públicas.

Desse modo, o novo modelo foi elaborado tendo como fundamentos: i) o compromisso 14 do terceiro plano de ação brasileiro na OGP: ampliar a participação social no PPA por meio do Fórum Interconselhos; e ii) o objetivo 16.7 dos ODS: garantir a tomada de decisão responsiva, inclusiva, participativa e representativa em todos os níveis. Na perspectiva de valorização das estruturas participativas já existentes, a metodologia previa a utilização dos conselhos nacionais, em articulação com as Subsecretarias de Planejamento, Orçamento e Administração (SPOAs) dos ministérios.

Especificamente, cada conselho foi convidado a identificar metas ou iniciativas do PPA mais relevantes segundo sua agenda política. Os elementos selecionados seriam objeto de um acompanhamento específico, com a elaboração de um plano de implementação simplificado e o fornecimento periódico de informaçóes, pelos órgãos de execução, e a apresentação de recomendaçóes,

7. 0 alinhamento do PPA com os ODS corroborou a perspectiva da Secretaria de Planejamento e Assuntos Econômicos (Seplan) sobre a aderência das demandas da sociedade à elaboração de metas e iniciativas do PPA. No caso da agenda LGBT, por exemplo, apesar de uma temática sensível, levantamentos da secretaria indicaram que das 192 resoluções aprovadas na 3a Conferência Nacional de Políticas Públicas de Direitos Humanos de Lésbicas, Gays, Bissexuais, Travestis e Transexuais apenas 48 não estavam presentes nos atributos do PPA, o que determinava uma compatibilização da ordem de $75 \%$ entre os dois elementos. 
pelos órgãos de participação social. Essa proposta, denominada monitoramento tempestivo, motivou o Fórum Interconselhos de novembro de 2017.

Uma das vantagens desse modelo seria a articulação do planejamento governamental com a estrutura dos órgãos de controle, nesse caso a Controladoria-Geral da União (CGU). Nessa proposta, a participação da CGU ocorreria no momento da execução das políticas públicas, diferentemente do modelo tradicional, em que sua participação se dá a posteriori, o que de maneira geral dificulta a tomada de decisóes que possam corrigir o rumo das políticas. No modelo proposto, a estrutura de controle da CGU, a partir da provocação feita pelos conselhos, poderia atuar no sentido de reforçar a implementação de políticas públicas estruturantes que não estivessem sendo executadas, ou ainda de modificar o rumo daquelas em desacordo com as demandas da sociedade civil.

A atuação da sociedade no monitoramento do PPA apresentava potencial de complementar a avaliação formal realizada continuamente pela burocracia estatal. Bezerra (2018) aponta, entretanto, que houve dificuldades para a sociedade desenvolver adequadamente a proposta de monitoramento estabelecida no âmbito do Fórum Interconselhos. Embora os conselhos, em geral, já tivessem o costume de acompanhar as açóes governamentais em torno do tema em que atuam, uma difusão do acompanhamento focado no PPA poderia trazer ganhos mais consistentes para as políticas públicas em determinadas áreas. É fundamental a democratização do acompanhamento do planejamento governamental, inclusive a partir de iniciativas oficiais que garantam recursos e instrumentos para essa efetivação, a fim de que ocorra um impacto positivo nos resultados em torno das contribuiçóes da sociedade no PPA.

Assim, infere-se que a contínua ampliação, desde 2011, daquelas ações que compóem a participação no PPA por meio do Fórum Interconselhos estava ocorrendo de forma a alcançar patamares importantes de inclusão da sociedade no planejamento federal. Os avanços a partir da regionalização do fórum, por exemplo, poderiam ser acompanhados de práticas mais recorrentes de inclusão social e de capacitação para esse debate, visando garantir estrutura e condiçóes adequadas para que os atores de diferentes espaços de participação, presentes no Fórum Interconselhos, propagassem as atividades iniciadas em cada edição.

\section{ELABORAÇÃO DO PPA 2020-2023}

Em 2019 foi elaborado o projeto de lei do PPA 2020-2023 sem incluir o Fórum Interconselhos, mas prevendo uma consulta pública em junho de 2019. Na mensagem presidencial, "o resultado apresentadocerca de 2.100 participaçóes, 193 propostas de alteração nos programas e 1.815 concordâncias das propostas - demonstrou o envolvimento da sociedade no novo PPA” (Brasil, 2019, p. 23).

\section{FATORES DE CONTINUIDADE E DESUSO}

Alguns fatores observados estimulariam a adoção do modelo participativo do Fórum Interconselhos. O primeiro seria a abrangência da função de planejamento, que, por alcançar todas as áreas governamentais, atrairia a atenção da sociedade civil. $\mathrm{O}$ segundo fator seria a atuação de um quadro humano ${ }^{8}$ responsável e comprometido com os órgãos de planejamento, considerando que "foram os servidores desses órgãos que tornaram realidade os diálogos dos últimos anos e que os mantêm até hoje" (Avelino, 2017, p. 204). Esses dois atributos podem ser considerados os maiores fatores de continuidade da participação social no PPA 2016-2019.

8. Com destaque para o quadro permanente composto majoritariamente por membros da carreira de analista de planejamento e orçamento. 
O enfraquecimento desses fatores explica o declínio da participação no PPA em 2019. Inicialmente, a função de planejamento foi esvaziada e o próprio plano perdeu a característica de agenda de desenvolvimento, absorvida pela Estratégia Nacional de Desenvolvimento Econômico e Social (Endes), em 2018. Quanto ao corpo técnico, houve um enxugamento com o fim do Ministério do Planejamento, Desenvolvimento e Gestão e a incorporação da Seplan pela Secretaria de Avaliação, Planejamento, Energia e Loteria.

Adicionalmente, a ausência de institucionalização daquelas práticas foi um fator de desestímulo. Mesmo nos PPAs anteriores, as estratégias adotadas não foram transformadas em lei, lacuna que as deixou a cargo de "iniciativas que promovem alguns avanços, mas permanecem abaixo do que a própria legislação exige" (Avelino, 2017, p. 200). Até 2018, esse vácuo normativo foi mitigado pela articulação com compromissos internacionais. A premiação pelo UNPSA, o alinhamento aos ODS e, principalmente, a inclusão na OGP são exemplos dessa tática. Diante da falta de legislaçáo nacional específica, compromissos internacionais ajudaram a suprir a lacuna.

O cenário mudou em 2019. O quarto plano de ação brasileiro na OGP 2018-2020 não mencionava mais a participação no planejamento governamental. Além disso, os conselhos nacionais enfrentaram, desde 2016, um cenário de restrição de recursos e de diminuição da autonomia. Ainda em 2019, a lacuna normativa aumenta com a revogação do Decreto no 8.243/2014. Não havia mais, portanto, o ecossistema participativo que alimentou o Fórum Interconselhos.

\section{CONCLUSÕES}

A análise da participação social no PPA 2016-2019 é uma crônica da ascensão e do declínio de um modelo participativo de planejamento público. Apesar da previsão na LRF, é possível concluir que a falta de institucionalização foi um fator decisivo para o declínio da participação no PPA. Para ser efetiva, a participação social tem que ser adotada como um método de governo, que compreende de fato a soberania popular e trabalha ativamente no compartilhamento de poder com a sociedade. Considerando os vícios da democracia representativa - principalmente as vantagens do poder econômico no sistema eleitoral -, a participação é um relevante complemento para a atuação política dos grupos marginalizados, que muitas vezes não obtêm representação adequada nas casas legislativas. Vem daí, provavelmente, a grita de muitos congressistas (Alencar e Ribeiro, 2014), para quem o modelo "usurparia" o poder dos representantes eleitos, mas que de fato apenas ampliaria minimamente a distribuição do poder, aumentando a pluralidade de interesses dentro do Estado, nos marcos da própria democracia liberal.

Nessa mesma perspectiva, a participação da sociedade não pode se restringir apenas ao momento da elaboração, devendo compreender todo o ciclo das políticas públicas. Quando isso não ocorre, ainda que as demandas sejam incorporadas ao sistema de planejamento, os diferentes atores técnicos e políticos podem estabelecer pontos de veto para sua efetiva implementação. Assim, a articulação entre Estado e sociedade civil deve ocorrer em todo o ciclo das políticas, para que possíveis correçóes de rumo possam ser tempestivamente realizadas e impedir o desvirtuamento das demandas apresentadas pela sociedade e oficialmente incorporadas pela burocracia do Estado.

Essas tensóes e lacunas estavam presentes desde as primeiras iniciativas participativas no planejamento federal. Havia, no entanto, entre 2003 e 2015, um contexto que foi rotulado anteriormente como um ecossistema participativo, formado por várias instâncias e mecanismos de 
participação social (conselhos, conferências, ouvidorias, audiências etc.) e animado por estímulos recíprocos, por parte do Estado e da sociedade civil, de continuidade ao diálogo. Esse cenário favorável, que não existe mais, produziu naquele período uma tolerância generalizada com a falta de institucionalização, apostando na perspectiva de um aperfeiçoamento constante.

Além disso, a função de planejamento fortalecida e uma equipe técnica comprometida aparecem como fatores de continuidade da participação no PPA 2016-2019. A mesma burocracia estatal, que poderia ser um fator inicial de resistência à abertura, pôde atuar como promotora ativa das práticas participativas, depois que foram incorporadas às rotinas e à cultura do órgão. Nesse sentido, a articulação com compromissos internacionais - como os ODS e a OGP - foi uma abordagem bem-sucedida, esgotada quando o governo federal passou a atuar de forma hostil à participação e ao planejamento governamental.

É desafiador consolidar a inclusão da sociedade em uma pauta tão complexa como o planejamento governamental a nível federal. Há ganhos significativos para o país quando as demandas sociais são devidamente processadas e refletidas em políticas públicas e açóes governamentais. Os avanços apresentados pelo modelo de participaçáo representado pelo Fórum Interconselhos são muito importantes para romper o isolamento da sociedade no debate sobre planejamento governamental. Trata-se de lidar com uma dinâmica que exige aprimoramento contínuo, já que não está isenta de limites e necessidades de mudança, para que se chegue à maneira mais inclusiva e democrática possível de buscar a consolidação dos objetivos em torno das práticas de participação social.

Em uma perspectiva técnica, o modelo participativo do PPA 2016-2019 ensinou muito sobre coordenação de órgãos e processos. Ele demonstrou, via ODS e monitoramento tempestivo, que é possível inserir a sociedade nas açóes estratégicas, sem concorrer com as instâncias existentes ou as competências governamentais. Do ponto de vista político, contudo, mostrou-se que isso não basta. A construção de um Estado inclusivo passa pelo fortalecimento democrático de sua função de planejamento e, em sentido reverso, também é ali que começa o fim de uma nação.

\section{REFERÊNCIAS}

ALENCAR, J. L. O.; RIBEIRO, U. C. O decreto sobre a participação social no governo federal e a "polêmica bendita". Boletim de Análise Político-Institucional, n. 6, p. 23-27, jun./nov. 2014.

AVELINO, D. Planejamento, orçamento e participação social. In: GIMENE, M.; COUTO, L. F. (Org.). Planejamento e orçamento público no Brasil. Brasília: Enap, 2017. p. 175-206.

BEZERRA, F. Fórum Interconselhos: análise da participação social no Plano Plurianual (PPA 2016-2019). 2018. Dissertação (Mestrado) - Instituto de Ciências Humanas, Universidade de Brasília, Brasília, 2018.

BRASIL. Fórum Dialoga Brasil no PPA 2016-2019: devolutiva - relato dos grupos de trabalho. Brasília: Secretaria Geral, 2015.

. Ministério do Planejamento, Orçamento e Gestão. Orientaçóes para o monitoramento participativo do PPA 2016. Brasília: Secretaria de Planejamento e Investimentos Estratégicos, 2016. 
Relatório de atividades: Comissão Nacional para os Objetivos de Desenvolvimento Sustentável - 2017-2018. Brasília: Presidência da República, 2018.

Lei no 13.971, de 27 de dezembro de 2019. Institui o Plano Plurianual da União para o período de 2020 a 2023. Diário Oficial da Uniáo, 27 dez. 2019. 